\title{
Biogenic synthesis of silver nanoparticles and their antioxidant and antibacterial activity
}

\author{
S. Bhakya ${ }^{1} \cdot$ S. Muthukrishnan ${ }^{2} \cdot$ M. Sukumaran ${ }^{1} \cdot$ M. Muthukumar ${ }^{2}$
}

Received: 23 May 2015/Accepted: 16 June 2015/Published online: 4 July 2015

(C) The Author(s) 2015. This article is published with open access at Springerlink.com

\begin{abstract}
Nanomedicine utilizes biocompatible nanomaterials for diagnostic and therapeutic purposes. The present study reports the use of Helicteres isora root extract for the synthesis of silver nanoparticles (AgNPs). The synthesized AgNPs were initially noticed through visual color change from yellow to reddish brown and further confirmed by surface plasmonic resonance (SPR) band at $450 \mathrm{~nm}$ using UV-visible spectroscopy. Morphology and size of AgNPs were determined by transmission electron microscopy (TEM) analysis. X-ray diffraction (XRD) study revealed crystalline nature of AgNPs. The prolonged stability of AgNPs was due to capping of oxidized polyphenols and carboxyl protein which was established by Fourier transform infrared spectroscopy (FTIR) study. In addition, the synthesized AgNPs were tested for antioxidant and antibacterial activities. It showed good antioxidant activity as compared to butylated hydroxytoluene (BHT) and ascorbic acid as standard antioxidant. It could be concluded that $H$. isora root extract can be used efficiently in the production of potential antioxidant and antibacterial AgNPs for commercial application.
\end{abstract}

Keywords Green synthesis - Silver nanoparticles · Helicteres isora, antioxidant · Antibacterial · TEM \& FTIR

S. Muthukrishnan

muthukrishnan1985@gmail.com

M. Sukumaran

sukukumar05@gmail.com

1 P.G. and Research Department of Zoology, Rajah Serfoji Govt. College (Autonomous), Thanjavur 613 005,

Tamil Nadu, India

2 Department of Plant Science, Bharathidasan University, Tiruchirappalli 620 024, Tamil Nadu, India

\section{Introduction}

Recent years researchers are interested on developing efficient method for the large-scale synthesis of nanoparticles (NPs). Nanomedicine is a rapidly developing and promising field that makes best use of inert metals like silver, gold and platinum to synthesize metallic nanoparticles with high therapeutic potential for various biomedical applications. Among all metal nanoparticles, silver nanoparticles (AgNPs) have much attention due to the surface plasmon resonance (SPR) (strong absorption in the visible region), which can be easily observed by UV-visible spectrophotometer (Krishnaraj et al. 2010). Silver with its potent antimicrobial activity has been used in the synthesis of silver nanoparticles which finds extensive use in the preparation of food processing, topical ointments and medical implants (Weiss et al. 2006; Wong 2012). Though the synthesis of silver nanoparticles has been carried out by various methods such those based on reduction in solution, chemical and photochemical reactions (Henglein 1998), decomposition of silver compounds by thermal method (Viet Quang and Hoai Chau 2013) and microwave-assisted process (Jiang et al. 2006), they involve the use of noxious chemicals. The green synthesis methods using plant extracts have been shown to be more advantageous owing to their simple methodology and eco-friendly nature (Muthukrishnan et al. 2015; Ramalingam et al. 2014; Kanipandian et al. 2014; Singh et al. 2013). Green synthesis of silver nanoparticles using various medicinal plants including, Acacia leucophloea (Murugan et al. 2014), Aegle marmelos (Nithya Deva Krupa and Raghavan 2014), Alstonia scholaris (Shetty et al. 2014), Solanum trilobatum, Syzygium cumini, Centella asiatica and Citrus sinensis (Logeswari et al. 2013), Crataegus douglasii (GhaffariMoghaddam et al. 2014) has been reported. Such green 
synthesized silver nanoparticles from Dillenia indica (Singh et al. 2013), Morinda pubescens (Inbathamizh et al. 2013), and Ceropegia thwaitesii (Muthukrishnan et al. 2015) have also been shown to exhibit in vitro antioxidant and antibacterial activities. With these evidences, this study was designed to synthesize AgNPs using aqueous Helicteres isora root extract and assess their antioxidant and antibacterial activity.

H. isora fruits are used as vermifuge, astringent, stomachic, vulnerary and useful in bowel gripes (Chopra et al. 1956). H. isora plant extracts possess anticancer properties (Mathew and Unnithan 1992). Usually, the root juice and bark were used against emphysema and diabetes. It is also used as expectorant, astringent, to condense gripping and a cure for snakebite (Kirtikar and Basu 1993; Singh et al. 1984). In traditional medicine, the root juice and bark are claimed to be useful in snake bite, diabetes, asthma, blood disorder, cough, colic, diarrhea, dysentery, stomach affections, intestinal infections, emphysema, and also as a urinary astringent (Shriram et al. 2008). The extract from the root and bark possess insulin-sensitizing, hypolipidemic activity and has the potential for use in the treatment of type-2 diabetes (Kumar et al. 2007). Moreover, the root extracts exhibited significant antihyperglycemic activity and the effect was comparable with that of glibenclamide (Venkadesh et al. 2004). Here, we report on the green synthesis of silver nanoparticles (AgNPs) from $H$. isora root extract, their physical characterization and their antioxidant and antibacterial activities.

\section{Materials and methods}

\section{Sample preparation}

Roots of $H$. isora were collected from Western Ghats of Tamil Nadu, washed with sterile distilled water and dried, then make it powder using mortar and pestle. $1 \mathrm{~g}$ of root powder was mixed with $100 \mathrm{ml}$ of water and kept on orbital shaker at $120 \mathrm{rpm}$ for $12 \mathrm{~h}$. After that, the extracts were filtered with Whatman No. 1 filter paper and stored at $4{ }^{\circ} \mathrm{C}$ in refrigerator until further use.

\section{Synthesis of silver nanoparticles (AgNPs)}

AgNPs were synthesized following the procedure of Geethalakshmi and Sarada (2010) with slight modification. AgNPs were synthesized by mixing aqueous $\mathrm{AgNO}_{3}$ solution $(1 \mathrm{mM})$ and root extracts in the ratio of $1: 1$ and incubating the mixture at room temperature for $6 \mathrm{~h}$. Following incubation, the AgNPs formed were collected by centrifugation at $18,000 \mathrm{rpm}$ for $20 \mathrm{~min}$. The collected pellet was washed three times with double distilled water, transferred to a Petri plate and dried at room temperature.

\section{Characterization of AgNPs}

The bioreduction of $\mathrm{Ag}^{+}$ion in solution was monitored using UV-visible spectrophotometer (UV-160v, Shimadzu, Japan). The size distribution of synthesized AgNPs in solution was analyzed by DLS particle size analyzer [ZETA Seizers Nanoseries (Malvern Instruments Nano ZS)]. The studies on size, morphology and composition of silver nanoparticles were performed by transmission electron microscopy (JEOL JEM2100 TEM) and energy dispersive X-ray spectrum (EDX). The purified AgNPs were examined for the presence of biomolecules using FTIR spectrum (Thermo Scientific Nicolet 380 FT-IR Spectrometer) and crystalline nature of AgNPs was determined by X-ray diffraction (XRD) analysis.

\section{Antibacterial assay}

Antibacterial activity of synthesized AgNPs was determined using disc diffusion method. The overnight inoculated bacterial cultures were spread over the freshly prepared Mueller-Hinton agar plates. The 6-mm sterile discs (Himedia) were kept on at Center of plate and different concentration of AgNPs (12.5, 25, 50 and $100 \mu \mathrm{g} /$ $\mathrm{mL}$ ) was poured on disc. The streptomycin disc (reference disc) was also kept on the plate incubated at $37{ }^{\circ} \mathrm{C}$ for $24 \mathrm{~h}$. The antimicrobial property of AgNPs was determined by measuring the zone of inhibition around the discs in diameter (millimeter) after incubation.

\section{In vitro antioxidant assays}

\section{DPPH free radical scavenging assay}

1,1-Diphenyl-2-picrylhydrazyl (DPPH) free radical scavenging potential of the AgNPs was determined using the modified method by Brand-Williams et al. (1995). Different concentrations $(10,20,30,40,50,75$ and $100 \mu \mathrm{g} / \mathrm{mL})$ of AgNPs and standard butylated hydroxytoluene (BHT) were taken in different test tubes. In the above samples, $1 \mathrm{~mL}$ of freshly prepared DPPH $(1 \mathrm{mM})$ dissolved in methanol was added and vortexed thoroughly. Finally, the solution was incubated in dark place for $30 \mathrm{~min}$. The absorbance of stable DPPH was recorded at $517 \mathrm{~nm}$. The DPPH (containing no sample) was used as a control prepared using the same procedure. Free radical scavenging 
activity was expressed as the percentage of inhibition that was calculated using the equation of

DPPH radical scavenging activity (\%)

$$
=(\mathrm{Ac}-\mathrm{As}) / \mathrm{Ac} \times 100 \text {, }
$$

where Ac is the control absorbance of DPPH radical + methanol; As is the sample absorbance of DPPH radical + sample AgNPs/standard BHT.

\section{Hydrogen peroxide scavenging assay}

The $\mathrm{H}_{2} \mathrm{O}_{2}$ scavenging activity was assayed by the modified method (Pick and Mizel 1981). In brief, different concentrations $(10,20,30,40,50,75$ and $100 \mu \mathrm{g} / \mathrm{mL})$ of AgNPs and ascorbic acid (control) were mixed with $50 \mu \mathrm{L}$ of $5 \mathrm{mM} \mathrm{H}_{2} \mathrm{O}_{2}$ solution (SD Fine Chem, Mumbai) and incubated at room temperature for $20 \mathrm{~min}$. The absorbance was measured at $610 \mathrm{~nm}$. The percentage of $\mathrm{H}_{2} \mathrm{O}_{2}$ scavenging was calculated using Eq. (1).

\section{Nitric oxide radical scavenging assay}

Nitric oxide radicals generated from sodium nitroprusside in aqueous at physiological $\mathrm{pH}$ interacts with oxygen to produce nitrite ions, which were measured by using the Griess reaction reagent was evaluated by modified method of Sousa et al. (2008). In brief, nitric oxide radicals, which were generated from $100 \mu \mathrm{l}$ of $20 \mathrm{mM}$ sodium nitroprusside, were incubated with $100 \mu \mathrm{l}(10,20,30,40,50,75$ and $100 \mu \mathrm{g} / \mathrm{mL}$ ) of AgNPs for $60 \mathrm{~min}$, at room temperature. BHT and NO• scavenger were used as a positive control. Nitric oxide radical scavenging assay was calculated by Eq. (1).

\section{Reducing power assay}

The reducing power was determined by Oyaizu's method (1986) with slight modification. In brief, different concentrations $(10,20,30,40,50,75$ and $100 \mu \mathrm{g} / \mathrm{mL})$ of AgNPs solution were mixed with $2.5 \mathrm{~mL}$ of phosphate buffer (200 mM, pH 6.6) and $2.5 \mathrm{~mL}$ of $1 \%$ potassium ferricyanide. The mixture was incubated at $50{ }^{\circ} \mathrm{C}$ for $20 \mathrm{~min}$ and then cooled rapidly. Subsequently, $2.5 \mathrm{~mL}$ of $10 \%$ TCA was added with the above-mentioned solution and centrifuged at $3000 \mathrm{rpm}$ for $8 \mathrm{~min}$. The collected supernatant was mixed with equal amount of Millipore Milli-Q water. Finally, $1 \mathrm{~mL}$ of $0.1 \%$ ferric chloride was added with the upper layer and the absorbance was measured spectrophotometrically at $700 \mathrm{~nm}$. The obtained results were compared with BHT which was used as a positive control. The percentage of reducing power was calculated by Eq. (1).

\section{Results and discussion}

\section{Characterization}

The present study elucidates the green synthesize of AgNPs from root extract of $H$. isora and their biological activity. NPs are generally characterized by their size, shape, surface area, and dispersity. Homogeneity of these properties is important in many applications (Jiang et al. 2006). When the root extract was mixed with $\mathrm{AgNO}_{3}$ and incubated at room temperature, within $30 \mathrm{~min}$ of the reaction, its color changed from brown to dark brown (Fig. 1b, c), indicating the formation of AgNPs. It is an efficient and rapid method, which was very well explained by other researchers who worked with different plant systems (Muthukrishnan et al. 2015; Kanipandian et al. 2014; Kalaiselvi et al. 2015). Change in color was due to the excitation of surface plasmon vibrations in metal nanoparticles (Ahmad et al. 2003). Our results are in conformed to Muthukrishnan et al. (2015), who reported the formation of AgNPs within $30 \mathrm{~min}$ of incubation. However, Nithya Deva Krupa and Raghavan (2014) reported color change after $24 \mathrm{~h}$ indicating the slow reduction of the $\mathrm{AgNO}_{3}$ by the aqueous fruit extract of Aegle marmelos. The variation in the rates of bioreduction observed may be due to the differences in the activities of the enzymes present in the plant root extracts.

\section{UV-visible spectra}

It is generally recognized that UV-Visible spectroscopy could be used to examine size and shape of controlled NPs in aqueous suspensions. This analysis showed the sharp

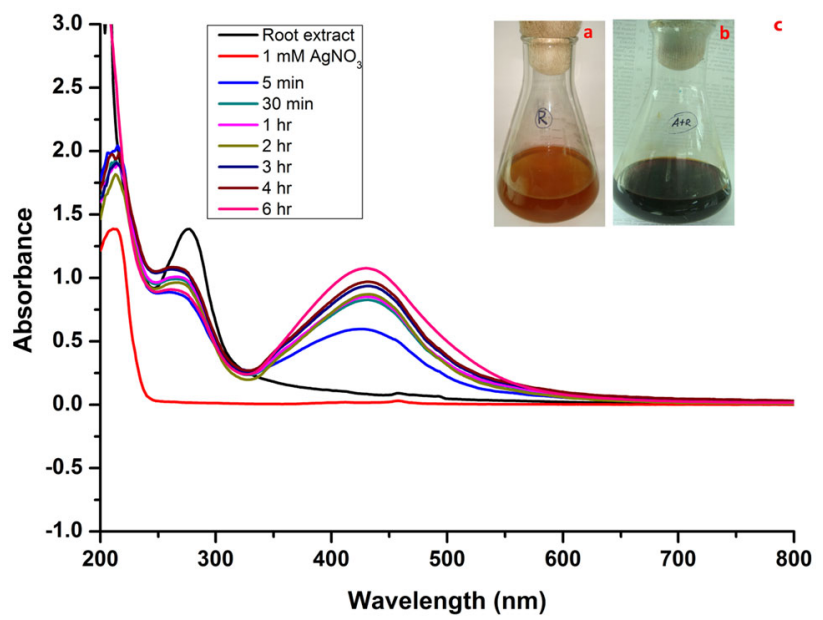

Fig. 1 UV-Vis spectra of synthesized AgNPs using root extract: $a$ extract; $b$ color changed after adding $\mathrm{AgNO}_{3} ; c$ different incubation times 
Fig. 2 DLS size distribution pattern of synthesized AgNPs using root extract

\section{Zeta Potential Distribution}

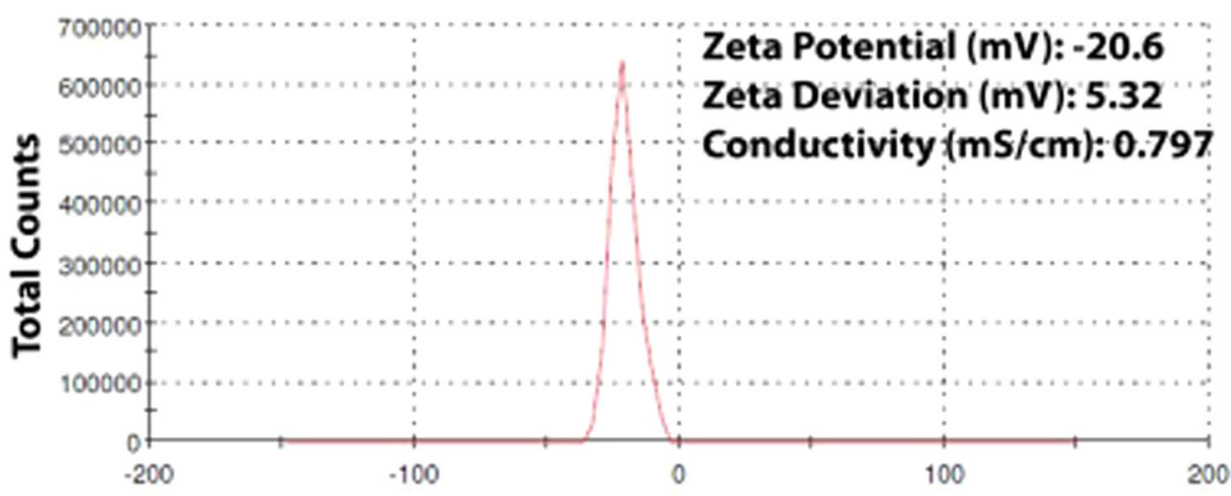

Zeta Potential (mV)

Size Distribution by Intensity

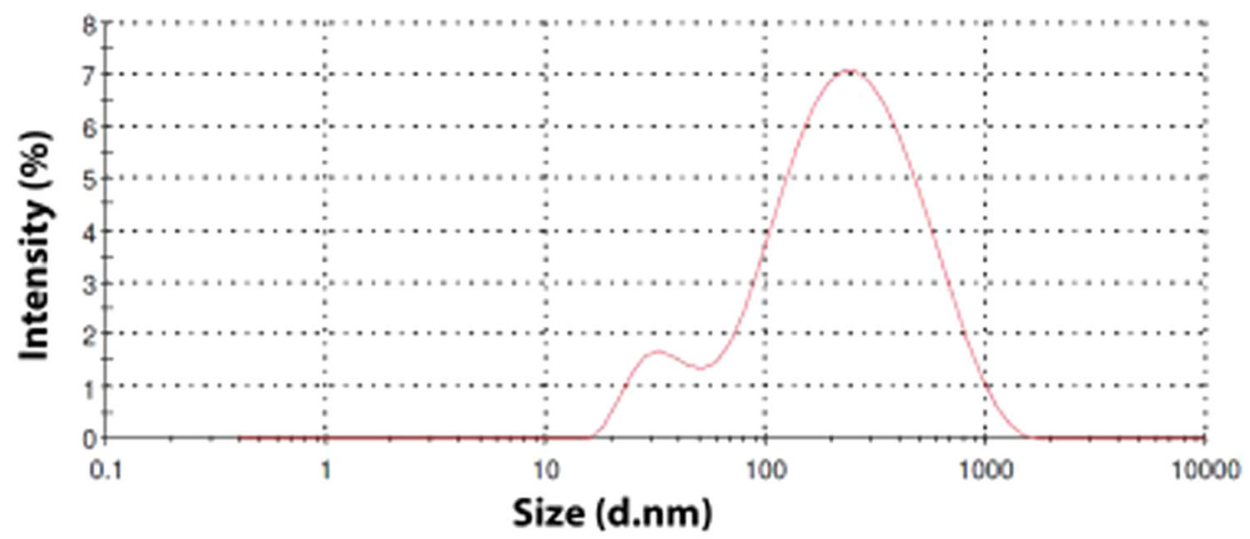

Size Distribution by Number

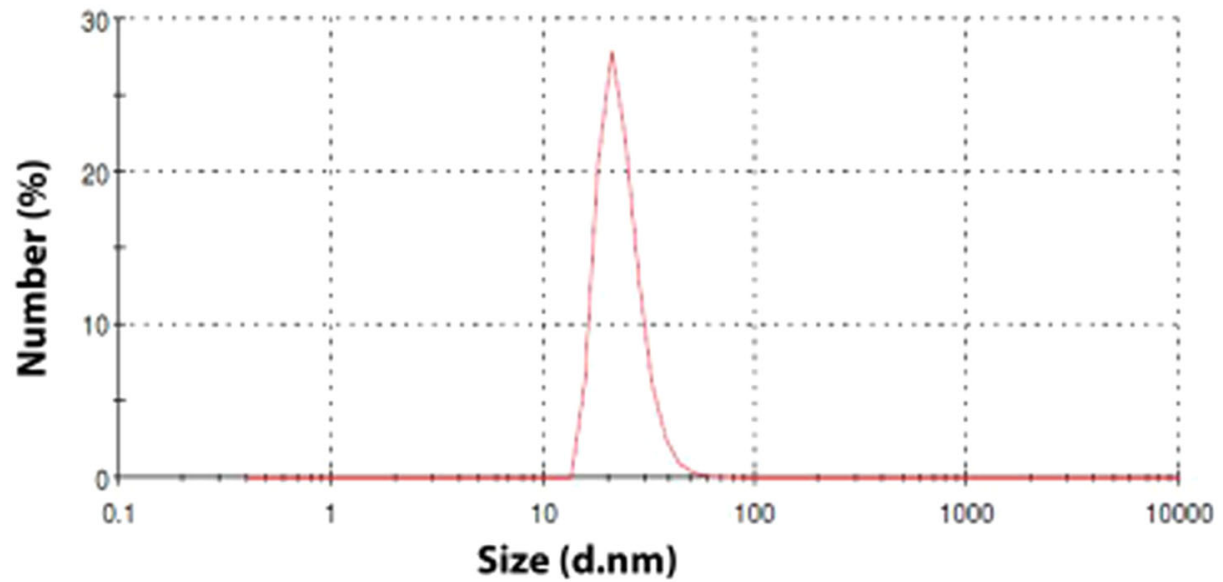

absorbance at around $450 \mathrm{~nm}$ (Fig. 1a), which was specific for AgNPs. The UV-Vis absorption band in the current visible light region $(420-450 \mathrm{~nm})$ is an evidence of the presence of surface plasmon resonance (SPR) of AgNPs (Ramalingam et al. 2014; Muthukrishnan et al. 2015;
Kanipandian et al. 2014). A single SPR band resembles to the spherical nanoparticles, whereas two or more SPR bands correspond to the anisotropic molecules (Krishnaraj et al. 2010). In the present study, two SPR band exhibited by the reaction mixture reveals the cubic shape (with $\mathrm{O}_{h}$ 
symmetry) of the AgNPs (Sands 1993). The intensity of the SPR peak increased with reaction time indicating the increasing concentration of AgNPs. The reduction was ascribed to the steroids, terpenoids, alkaloids, carbohydrate and phenolic compounds present in the extract (Suthar et al. 2009).

\section{$D L S$}

DLS was employed to analyzing quantitative size distributions and a more precise quantity of monodispersity in colloidal solutions. The differential intensity, number and zeta potential related to particle size distributions of the biosynthesized AgNPs were obtained from DLS study (Fig. 2a-c). The average particle intensity and number was found to be $86.2 \mathrm{~nm}$. The zeta potential of the colloidal solution was found to be $-20.6 \mathrm{mV}$. The size of the particle was much more than TEM and XRD results (Kumar et al. 2014). The larger particle size and more polydispersity observed by DLS as compared to TEM are due to the fact that the measured size also included the biomaterials covering the surface of silver nanoparticles.

\section{FTIR spectral analysis}

FTIR spectrum of the synthesized AgNPs is shown in Fig. 3 which reveals the possible biomolecules present in the root extract which is accountable for the reduction of silver ions and its interaction with the AgNPs. The IR spectrum of AgNPs shows intense bands at 3434.59, 2927.41, 2842.56, 1630.51, 1385.60 and $1024.01 \mathrm{~cm}^{-1}$. The IR spectrum of root extract shows intense bands at $3488.59,2930.30,2867.63,1653.66$ and $1096.26 \mathrm{~cm}^{-1}$ (Fig. 3), and significant difference was observed between the spectral positions of IR bands in root extract and biosynthesized AgNPs due to the reduction process. The broad band at $3434.59 \mathrm{~cm}^{-1}$ corresponds to the strong stretching vibrations of hydroxyl group $(-\mathrm{OH})$ of phenolic compounds; this broad band was reduction from root extract of $3488.59 \mathrm{~cm}-1$. The sharp two intense peaks at $2927.41,2842.56 \mathrm{~cm}^{-1}$ can be attributed to the $-\mathrm{O}-\mathrm{H}-$ and $\mathrm{C}=\mathrm{O}$ stretching vibrations, which indicates the presence of for aromatic and carbonyl groups of the protein and metabolites present in the root extract that may be involved in the reduction process (Kalyanasundaram et al., 2012). The IR spectrum of root extract exhibits a strong band at $1653.66 \mathrm{~cm}^{-1}$ corresponding to the $\mathrm{C}=\mathrm{O}$ (amide I) stretching mode and this peak shifted to $1630.51 \mathrm{~cm}^{-1}$ suggesting the possible association of the above-mentioned groups in AgNP synthesis. This amide I band indicates that proteins can bind to $\mathrm{Ag}^{+}$through carboxylate ions or free amine groups (Kumar et al. 2014). The IR band at $1024.01 \mathrm{~cm}^{-1}$ can be attributed to the $-\mathrm{C}-\mathrm{O}-$ stretching

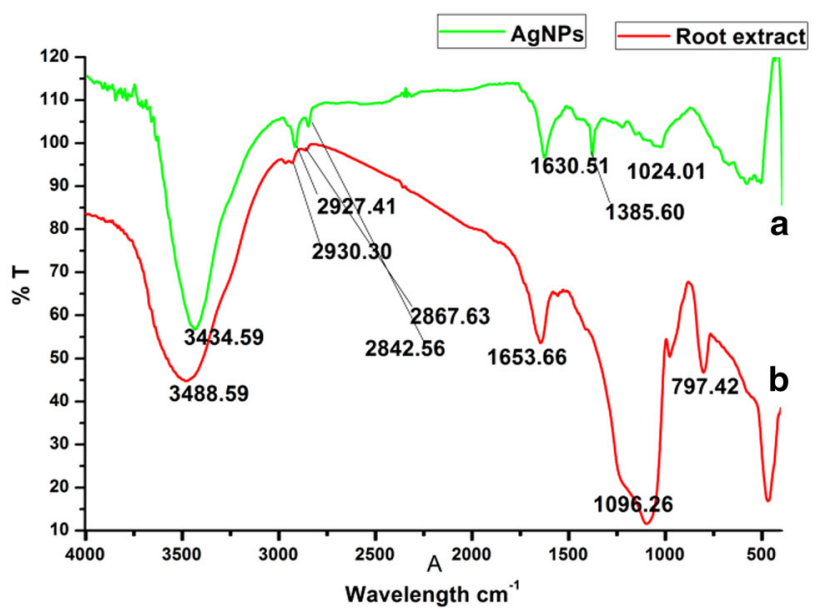

Fig. 3 FTIR analysis of green syntesized AgNPs; $a$ biosynthesized silver nanoparticles; $b$ root extract

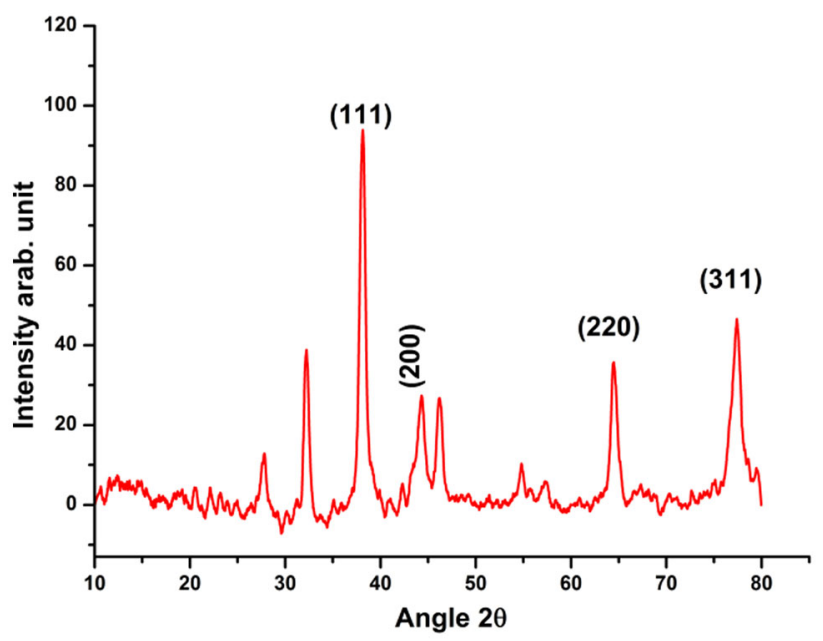

Fig. 4 XRD pattern of biosynthesized silver nanoparticles using root extract

vibrations of carboxylic acid, ester, and ether groups of the proteins present in the extract and this peak shifted to $1096.26 \mathrm{~cm}^{-1}$. The bend at $1388.5 \mathrm{~cm}^{-1}$ indicated the presence of $\mathrm{C}-\mathrm{H}$ group. Thus, from the IR spectrum, it may be assumed that these biomolecules act in the bioreduction as well as in the stabilization of biosynthesized AgNPs.

\section{$X R D$}

The X-ray diffraction pattern of the biosynthesised AgNPs from the root extract is shown in Fig. 4. Five distinct peaks at $38.12^{\circ}, 44.38^{\circ}, 64.45^{\circ}$ and $77.41^{\circ}$ indicated the (111), (200), (220) and (311) reflections of metallic silver. XRD pattern also represents the face-centered cubic structure of silver. A sharp and strong diffraction peak centered at 38 . $12^{\circ}$ was appeared, which can be indexed to the (111) 
Fig. 5 EDX spectrum shows strong peak of silver metal of biosynthesized silver nanoparticles

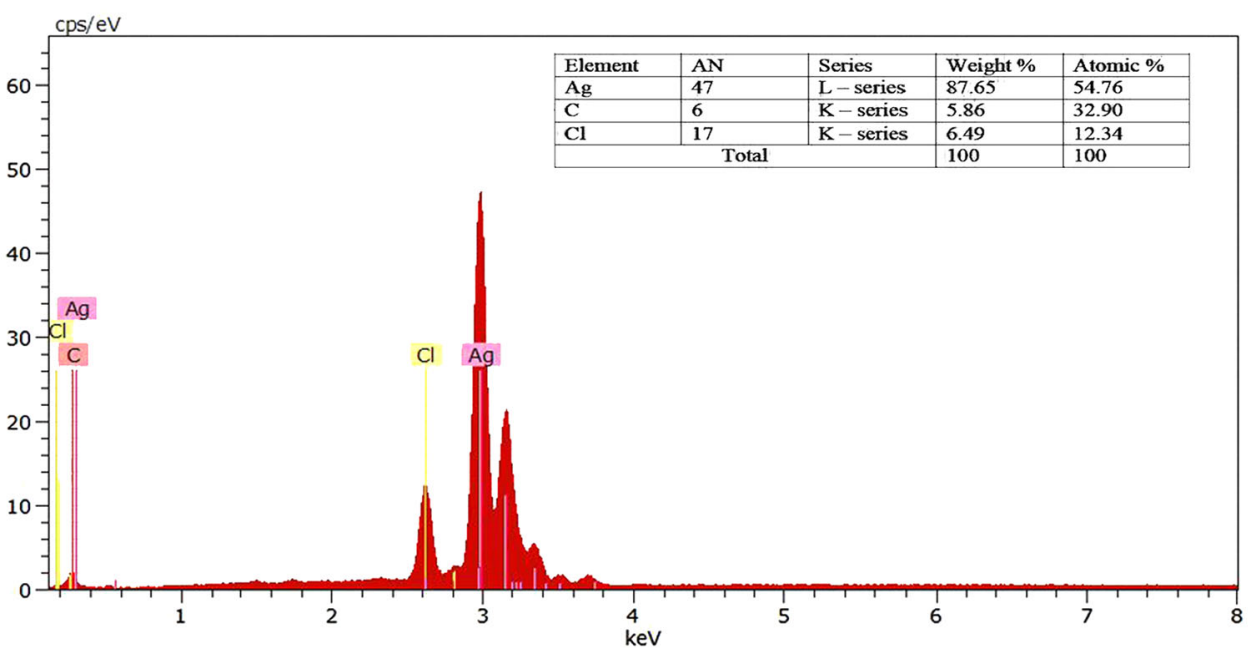

reflection and closely matched the reported reference values of Joint Committee on Power Diffraction Standards (JCPDS pdf no: 89-3722). The sharp peaks clearly indicate the cubic crystalline nature of the synthesized nanoparticles which is in nanoregime and agreement with the earlier reports. The average crystallite size of the silver nanoparticles estimated by the Debye-Scherrer formula calculated value is $43.25 \mathrm{~nm}$ which was higher than average size of the TEM analysis (Ramalingam et al. 2014; Muthukrishnan et al. 2015).

\section{EDX analysis}

The occurrence of the elemental silver can be identified by the EDX analysis (Fig. 5), which indicated the reduction in silver ions to silver element in the reaction mixture. The EDX spectrum illustrated the presence of strong metallic Ag signals. It confirmed the elemental constituents of silver $(87.65 \%)$, chlorine $(6.49 \%)$ and carbon $(5.86 \%)$, respectively. The most principal sharp signal was observed at $\sim 3 \mathrm{keV}$ for silver, which is distinctive for the absorption of crystalline nature of biosynthesized AgNPs (Muthukrishnan et al. 2015; Kanipandian et al. 2014; Ramalingam et al. 2014).

\section{TEM-SAED study}

The TEM micrographs of the synthesized AgNPs at different magnifications are shown in Fig. 6. It was found that AgNPs were spherical in shape with maximum particles in the size range of 16-95 $\mathrm{nm}$ (Fig. 6h). Figure 6a shows the biomolecular coating on the surface layer of AgNPs, which is responsible for enhanced stability of AgNPs. The SAED pattern is shown in Fig. $6 \mathrm{f}, \mathrm{g}$ and confirmed the presence of elemental AgNPs. It was also observed that AgNPs were monodispersed with low polydispersity index (PDI). The SAED pattern was agreed to the XRD analysis. The average crystallite size of the silver nanoparticles was estimated $38.23 \mathrm{~nm}$ (Fig. 6b-e). The TEM image showed the lattice fringes between the two adjacent planes to be $2 \mathrm{~nm}$ apart which corresponds to the interplanar separation of the (111) plane of face-centered cubic silver (Sharma et al. 2014).

Mechanism of reduction of $\mathrm{AgNO}_{3}$ to $\mathrm{AgNPs}$ by the phytoconstituents

The major phytoconstituents present in the root extract of $H$. isora are steroidal sapogenins belonging to triterpenes group (Diosgenin, neolignans and rosmarinic) ( $\mathrm{Li}$ et al. 2011; Patel et al. 2012; Kumar et al. 2007). The possible mechanism for the reduction of $\mathrm{Ag}^{+}$is projected and presented in Eq. (2). In this scheme, $\mathrm{Ag}^{+}$ions can form intermediate complexes with sapogenin $(-\mathrm{OH} / \mathrm{C}=\mathrm{O})$ hydroxyl group or carboxyl group present in steroidal sapogenin of triterpenes, which subsequently undergo reduction to $\mathrm{COOH}$ forms with consequent reduction of $\mathrm{Ag}^{+}$to AgNPs.

$$
\begin{aligned}
\mathrm{AgNO}_{3}+\mathrm{R}-\mathrm{C}=\mathrm{H} & \rightarrow\left[\mathrm{R}-\mathrm{C}=\mathrm{O} \ldots \mathrm{Ag}^{+} \ldots \mathrm{R}-\mathrm{H}=\mathrm{O}\right] \\
& \rightarrow \mathrm{Ag}^{+} \mathrm{RCOOH}^{+}+\mathrm{NO}_{3}^{+}(\mathrm{AgNPs})
\end{aligned}
$$

\section{Antioxidant activity}

\section{DPPH assay}

DPPH is a more stable and well-known free radical based on the reduction of accepting hydrogen or electron from donors. The DPPH reducing ability of the AgNPs was assessed by observing color change and the control does 
Fig. 6 TEM micrograph showing size of AgNPs with SAED pattern
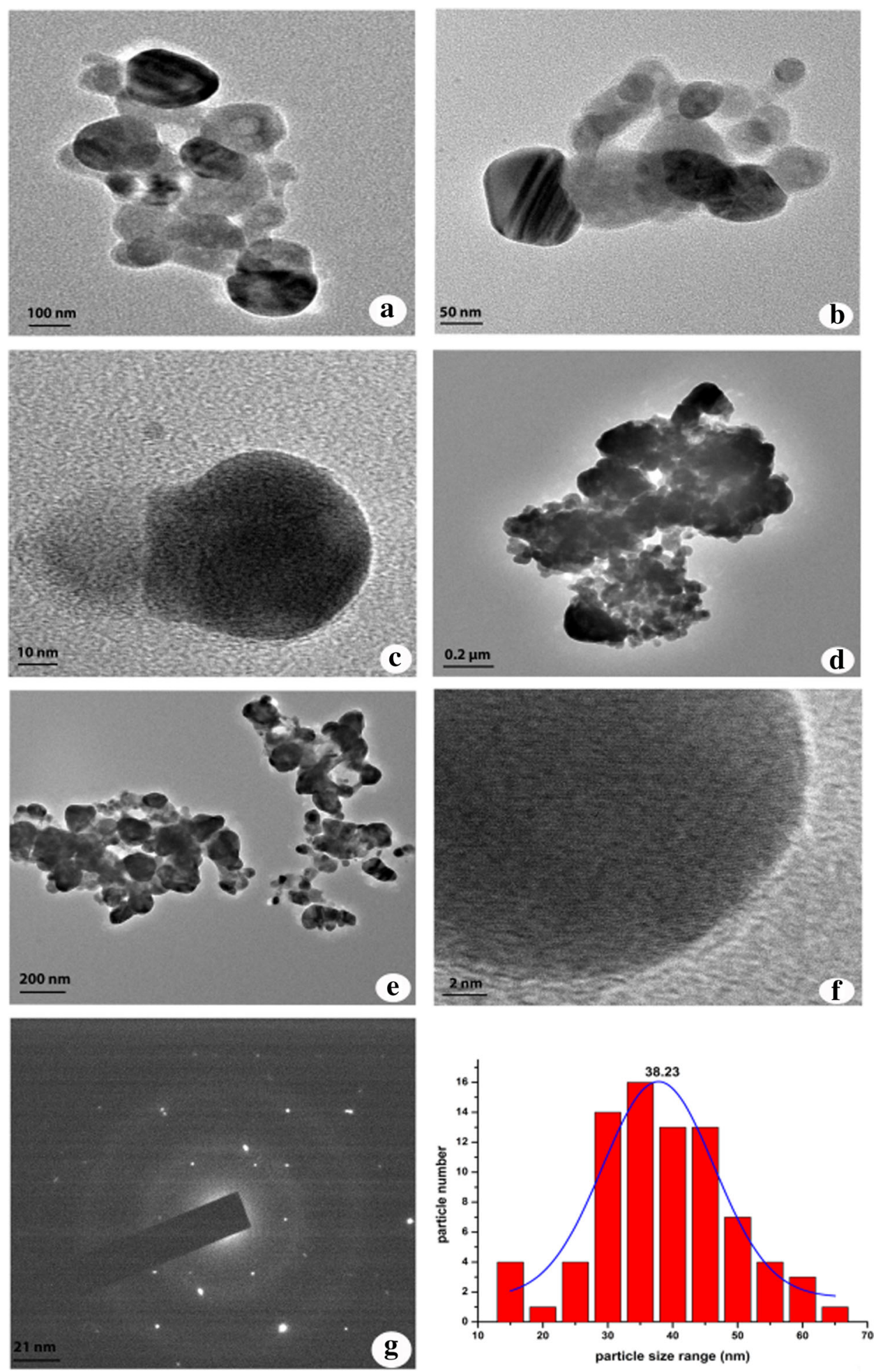

not show any color change. The DPPH scavenging assay exhibited effective inhibition activity of AgNPs when compared with the standard, BHT (Fig. 7a). The DPPH activity of the AgNPs was found to increase in a dosedependent manner. However, the AgNPs exhibited more inhibition with $90 \%$ scavenging activity of DPPH. When adding AgNPs in the DPPH solution, color change was occur which is due to the scavenging of DPPH due to donation of hydrogen atom to stable the DPPH molecule which is responsible for the absorbance of $517 \mathrm{~nm}$ 

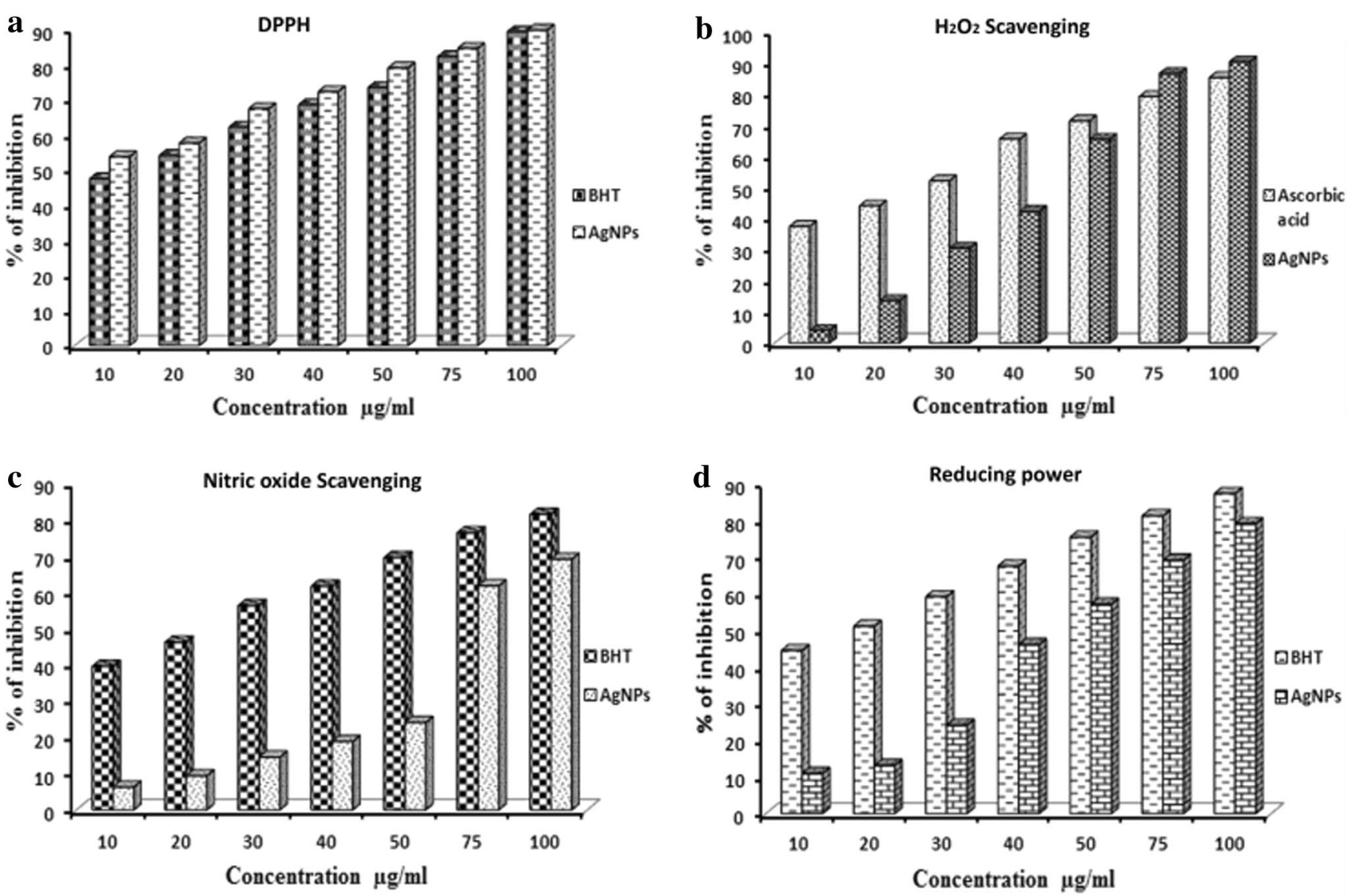

Fig. 7 Antioxidant activity of biosynthesized AgNPs

(Molyneux 2004; Kanipandian et al. 2014). The antioxidant potential of AgNPs could be attributed to functional groups adhered to them which were originated from the root extract.

\section{Measurement of $\mathrm{H}_{2} \mathrm{O}_{2}$ scavenging assay}

In living systems, uninhibited accumulation of $\mathrm{H}_{2} \mathrm{O}_{2}$ leads to the development of oxygen free radicals like peroxide and hydroxyl radicals which causes huge damage to cell membranes. The hydrogen peroxide scavenging activity of AgNPs was quantified spectrophotometrically using ascorbic acid as a standard and is shown in Fig. 7b. The concentrations at $100 \mu \mathrm{g} / \mathrm{mL}$ inhibition were found to be 93.31 and $85.35 \%$ for the AgNPs and ascorbic acid, respectively. Interestingly, $\mathrm{H}_{2} \mathrm{O}_{2}$ free radical was consistently higher than those obtained for DPPH scavenging activity. Surprisingly, the AgNPs exhibited comparatively better reducing power than ascorbic acid due to the structure and characterization of the AgNPs. In the presence of hydrogen peroxide, the dispersed AgNPs can induce reactive oxygen species like hydroxyl radicals. Hydrogen peroxide inside a cell at a low dose can accelerate the dissolution of AgNPs and produce much stronger oxidative stress (He et al. 2012). AgNPs can produce greater accounts of hydrogen peroxide and induce greater inflammasome formation because they can cause stronger leakage of cathepsins from impaired lysosomes and efflux of $\mathrm{K}^{+}$ ions may contribute to the production of superoxide and hydrogen peroxide in the membranes of mitochondria (Yang et al. 2012). Our results are in good accordance with an earlier report on the $\mathrm{H}_{2} \mathrm{O}_{2}$ scavenging effect of leaf extract of Abutilon indicum (Mata et al. 2015).

\section{Nitric oxide scavenging activity}

Nitric oxide (NO) is an important bioregulatory molecule in the nervous, immune and cardiovascular systems (Rees et al. 1989). The biosynthesized AgNPs showed a concentrationdependent activity in NO scavenging activity and the best activity $80.46 \%$ scavenging was observed at a higher concentration of $100 \mu \mathrm{g} / \mathrm{mL}$ (Fig. 7c). The above-observed NO activity was lesser than that of the standard BHT $(81.35 \%)$. It may be the interaction between AgNPs and nitric oxide (NO) under anhydrous, anaerobic conditions at room temperature and the NO radical which is very less stable with 

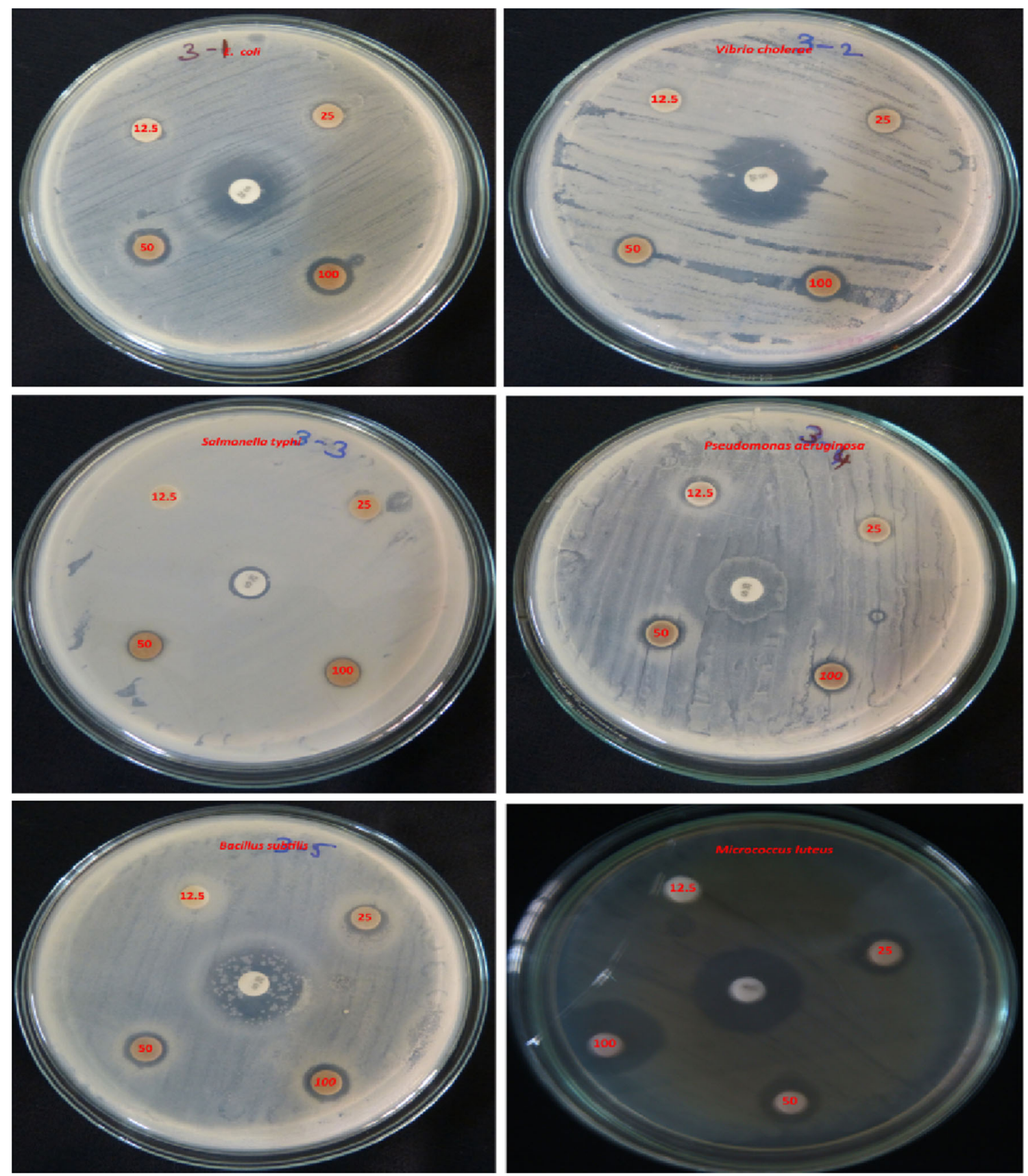

Fig. 8 Antibacterial effects of green synthesized AgNPs from $H$. isora

high electronegativity can easily accept electron from silver nanoparticles. (Rodriguez-Gattorno et al. 2002).

\section{The reducing power}

Figure $7 \mathrm{~d}$ shows the dose-dependent response for the reducing powers of the biosynthesized AgNPs of root extracts. Reducing power was increased consistently with increasing the concentration of AgNPs. Surprisingly, the AgNPs exhibited comparatively better reducing power than standard (BHT) due to the presence of phytoconstituents in the extracts. However, these phytoconstituents like steroidal saponins also have electron-donating antioxidant capacity (Lin et al. 1996). This result was correlated with biosynthesized AgNPs of Iresine herbstii (Dipankar and Murugan 2012).

\section{Antibacterial activity}

The AgNPs exhibited good antibacterial activity against both Gram-negative and Gram-positive bacteria (Fig. 8). But it showed higher antibacterial activity against $S$. typhi and $P$.

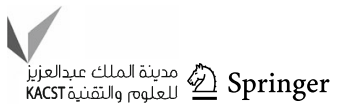




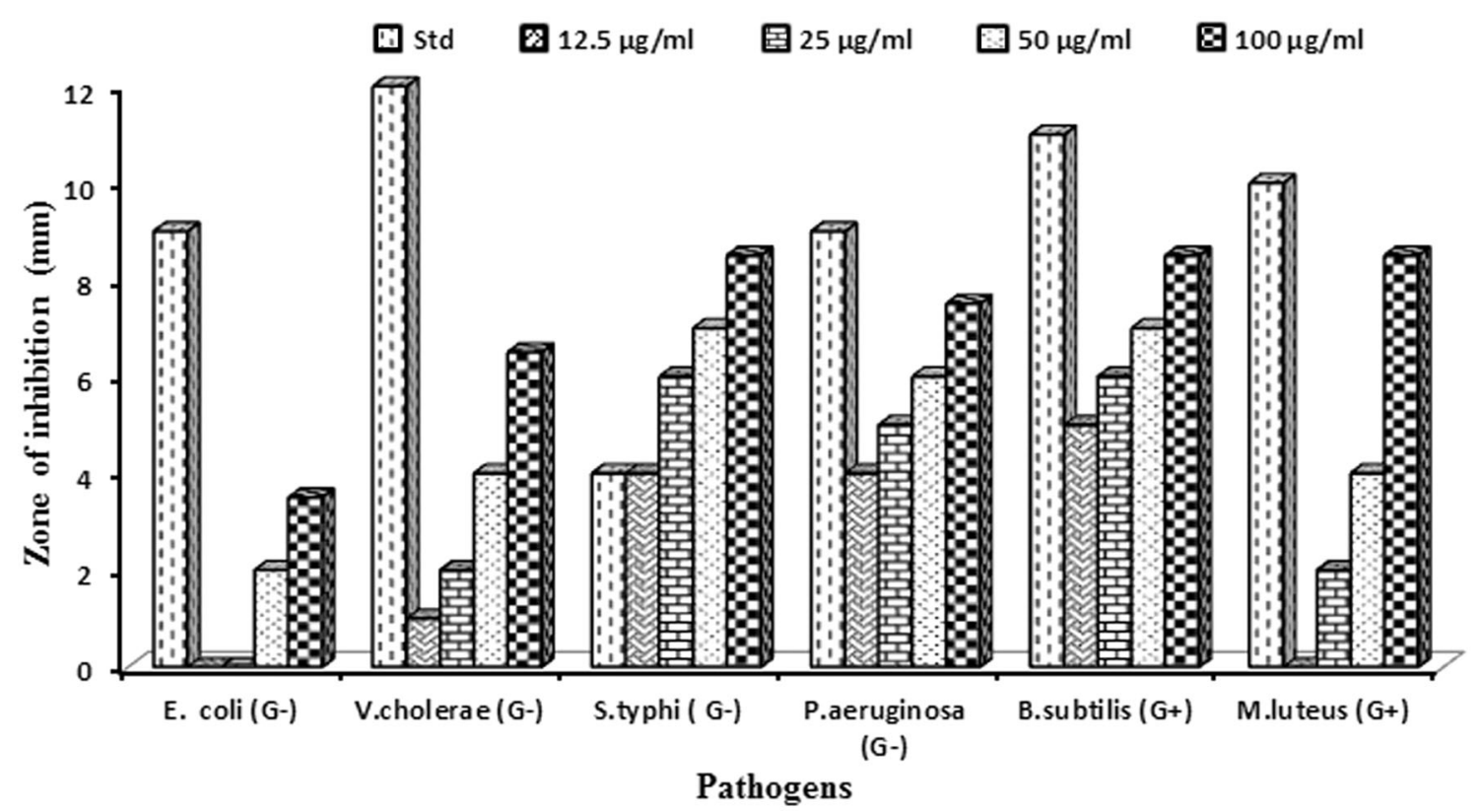

Fig. 9 Antibacterial activity of synthesized AgNPs against various pathogenic bacterial strains

aeruginosa (Gram negative) than B. subtilis and M. luteus (Gram positive) (Fig. 9). This result is possible due to the difference in the structure of the cell wall between Grampositive and Gram-negative bacteria. However, zone of inhibition was observed less in E. coli and V. cholerae (Gram positive), these results indicate that AgNPs show very less antibacterial activity against these microorganisms. Peptidoglycan is composed of a thick layer of bacterial cell wall, consisting of linear polysaccharide chains cross-linked by short peptides thus forming more rigid structure leading to difficult penetration of the AgNPs (Chaloupka et al. 2010). This high bactericidal activity is certainly due to the silver cations released from AgNPs that act as reservoirs for the $\mathrm{Ag}^{+}$bactericidal agent (Paszek et al. 2012). Therefore, AgNPs were widely used in antibacterial coatings in processing of medical instruments (Eby et al. 2009) and food industries for packaging (Krishnaraj et al. 2010). The biologically synthesized AgNPs using different plant extracts also showed a similar potent bactericidal activity (Muthukrishnan et al. 2015; (Logeswari et al. 2013; Murugan et al. 2014; Nithya Deva Krupa and Raghavan 2014).

\section{Conclusion}

AgNPs have emerged as a typical antimicrobial nanomaterial applied in industry, daily life, and medicine. Due to the strong activity of AgNPs and release of Ag ions, the biological properties and safety thereof have attracted tremendous attentions from scientists in recent era. A simple, stable and eco-friendly method of biosynthesizing
AgNPs was successfully developed using $H$. isora root extract. H. isora root contains more triterpenes that play major roles as reducing as well as capping agents for use in synthesis of AgNPs. The extract acts as both reducing and stabilizing agent which was confirmed by FTIR studies. TEM and XRD reports revealed that synthesized AgNPs were crystalline in nature with an average particle size of 30-40 nm. This biosynthesized AgNPs were found to be multifunctional with good antioxidant activities. This biosynthesized method facilitates best alternative for both chemical and other physical methods. Hence, this method can be employed in large-scale production and can be used in many medicinal and technological applications.

Acknowledgments The work was financially supported by University Grant Commission-Rajiv Gandhi National Fellowship (UGC-RGNF) (No: F1-17.1/2013-14/RGNF-2013-14-SC-TAM44942. (SA-III)) University Grant Commission New Delhi, India to the first author. We thank sophisticated analytical instrument facility (SAIF), North-Eastern Hill University (NEHU), Shillong for accessing TEM facility. The authors wish to thank the following individuals who provided valuable advice in the final stage of the revision process: V. Ramalingam, Research Scholar (Department of Marine science, Bharathidasan University, Tiruchirappalli, 620 024, Tamil Nadu, India), N. Kanipandian \& KS Rajkumar (Research Scholars, Department of Animal Science, Bharathidasan University, Tiruchirappalli, 620 024, India).

Open Access This article is distributed under the terms of the Creative Commons Attribution 4.0 International License (http://creativecommons.org/licenses/by/4.0/), which permits unrestricted use, distribution, and reproduction in any medium, provided you give appropriate credit to the original author(s) and the source, provide a link to the Creative Commons license, and indicate if changes were made. 


\section{References}

Ahmad A, Mukherjee P, Senapati S, Mandal D, Khan MI, Kumar R (2003) Extracellular biosynthesis of silver nanoparticles using the fungus Fusarium oxysporum. Coll Surf B Biointerfaces 28:313-318

Brand-Williams W, Cuvelier ME, Berset C (1995) Use of a free radical method to evaluate antioxidant activity. Food Sci Technol-LWT 28:25-30

Chaloupka K, Malam Y, Seifalian AM (2010) Nanosilver as a new generation of nanoproduct in biomedical applications. Trends Biotechnol 28(11):580-588

Chopra RN, Chopra IC, Handa KL, Kapoor LD (1956) Glossary of medicinal Plants. CSIR, New Delhi, p 131

Dipankar C, Murugan S (2012) The green synthesis, characterization and evaluation of the biological activities of silver nanoparticles synthesized from Iresine herbstii leaf aqueous extracts. Coll Surf B Biointerfaces 98:112-119

Eby DM, Luckarift HR, Johnson GR (2009) Hybrid antimicrobial enzyme and silver nanoparticle coatings for medical instruments. ACS Appl Mater Interfaces 1(7):1553-1560

Geethalakshmi R, Sarada DVL (2010) Synthesis of plant-mediated silver nanoparticles using Trianthema decandra extract and evaluation of their anti microbial activities. Int J Eng Sci Tech 2(5):970-975

Ghaffari-Moghaddam M, Hadi-Dabanlou R, Khajeh M, Rakhshanipour M, Shameli K (2014) Green synthesis of silver nanoparticles using plant extracts. Korean J Chem Eng 31(4):548-557

He W, Zhou YT, Wamer WG, Boudreau MD, Yin JJ (2012) Mechanisms of the $\mathrm{pH}$ dependent generation of hydroxyl radicals and oxygen induced by Ag nanoparticles. Biomaterials 33(30):7547-7555

Henglein A (1998) Colloidal silver nanoparticles: photochemical preparation and interaction with $\mathrm{O} 2, \mathrm{CCl} 4$, and some metal ions. Chem Mater 10(1):444-450

Inbathamizh L, Ponnu TM, Mary EJ (2013) In vitro evaluation of antioxidant and anticancer potential of Morinda pubescens synthesized silver nanoparticles. J pharm Res 6(1):32-38

Jiang H, Moon K, Zhang Z, Pothukuchi S, Wong CP (2006) Variable frequency microwave synthesis of silver nanoparticles. J Nanopart Res 8(1):117-124

Kalaiselvi A, Roopan SM, Madhumitha G, Ramalingam C, Elango G (2015) Synthesis and characterization of palladium nanoparticles using Catharanthus roseus leaf extract and its application in the photo-catalytic degradation. Spectrochim Acta A Mol Biomol Spectrosc 135:116-119

Kalyanasundaram GT, Doble M, Gummadi SN (2012) Production and downstream processing of $(1 \rightarrow 3)$ - $\beta$-D-glucan from mutant strain of Agrobacterium sp. ATCC 31750. AMB Express 2(1):31

Kanipandian N, Kannan S, Ramesh R, Subramanian P, Thirumurugan R (2014) Characterization, antioxidant and cytotoxicity evaluation of green synthesized silver nanoparticles using Cleistanthus collinus extract as surface modifier. Mater Res Bull 49:494-502

Kirtikar KR, Basu BD (1993) Indian Medicinal plants, 2nd edn, vol 1, pp 371-372. Lalit Mohan Basu, Allahabad

Krishnaraj C, Jagan EG, Rajasekar S, Selvakumar P, Kalaichelvan PT, Mohan N (2010) Synthesis of silver nanoparticles using Acalypha indica leaf extracts and its antibacterial activity against water borne pathogens. Coll Surf B Biointerfaces 76(1):50-56

Kumar G, Banu GS, Murugesan AG, Rajasekara-Pandian M (2007) Preliminary toxicity and phytochemical studies of aqueous bark extract of Helicteres isora L. Int J Pharm 3:96-100

Kumar B, Smita K, Cumbal L, Debut A (2014) Synthesis of silver nanoparticles using Sacha inchi (Plukenetia volubilis L.) leaf extracts. Saudi J Boil Sci 21(6):605-609
Li P, Mao Z, Lou J, Li Y, Mou Y, Lu S, Zhou L (2011) Enhancement of diosgenin production in Dioscorea zingiberensis cell cultures by oligosaccharides from its endophytic fungus Fusarium oxysporum Dzf17. Molecules 16(12):10631-10644

Lin YL, Juan IM, Chen YL, Liang YC, Lin JK (1996) Composition of polyphenols in fresh tea leaves and associations of their oxygenradical-absorbing capacity with antiproliferative actions in fibroblast cells. J Agric Food Chem 44:1387-1394

Logeswari P, Silambarasan S, Abraham J (2013) Ecofriendly synthesis of silver nanoparticles from commercially available plant powders and their antibacterial properties. Sci Iran 20(3):1049-1054

Mata R, Nakkala JR, Sadras SR (2015) Biogenic silver nanoparticles from Abutilon indicum: their antioxidant, antibacterial and cytotoxic effects in vitro. Coll Surf B Biointerfaces 128:276-286

Mathew PJ, Unnithan MC (1992) Search for plant having anticancer properties used by the tribal of Wayanad, Malappuram and Palghat districts of Kerala, India. Aryavaidyan 6(1):54-60

Molyneux P (2004) The use of the stable free radical diphenylpicrylhydrazyl (DPPH) for estimating antioxidant activity. Songklanakarin J Sci Technol 26(2):211-219

Murugan K, Senthilkumar B, Senbagam D, Al-Sohaibani S (2014) Biosynthesis of silver nanoparticles using Acacia leucophloea extract and their antibacterial activity. Int J Nanomed 9:2431-2438

Muthukrishnan S, Bhakya S, Kumar TS, Rao MV (2015) Biosynthesis, characterization and antibacterial effect of plant-mediated silver nanoparticles using Ceropegia thwaitesii-An endemic species. Ind Crops Prod 63:119-124

Nithya Deva Krupa A, Raghavan V (2014) Biosynthesis of silver nanoparticles using Aegle marmelos (Bael) fruit extract and its application to prevent adhesion of bacteria: a strategy to control microfouling. Bioinorg Chem Appl 2014:1-8

Oyaizu M (1986) Studies on products of browning reactions: antioxidative activities of products of browning reaction prepared from glucosamine. Jpn J Nutr 44:307-315

Paszek E, Czyz J, Woźnicka O, Jakubiak D, Wojnarowicz J, Łojkowski W, Stępień E (2012) Zinc oxide nanoparticles impair the integrity of human umbilical vein endothelial cell monolayer in vitro. J Biomed Nanotechnol 8(6):957-967

Patel K, Gadewar M, Tahilyani V, Patel DK (2012) A review on pharmacological and analytical aspects of diosgenin: a concise report. Nat Prod Bioprospect 2(2):46-52

Pick E, Mizel D (1981) Rapid microassays for the measurement of superoxide and hydrogen peroxide production by macrophages in culture using an automatic enzyme immunoassay reader. J Immunol Methods 46(2):211-226

Ramalingam V, Rajaram R, Premkumar C, Santhanam C, Dhinesh P, Vinothkumar S, Kaleshkumar K (2014) Biosynthesis of silver nanoparticles from deepsea bacterium Pseudomonas aeruginosa JQ989348 for antimicrobial, antibioflim and cytotoxic activity. J Basic Microbiol 54:928-936

Rees DD, Palmer RM, Moncada S (1989) Role of endotheliumderived nitric oxide in the regulation of blood pressure. Proc Natl Acad Sci USA 86:3375-3378

Rodriguez-Gattorno G, Diaz D, Rendon L, Hernandez-Segura GO (2002) Metallic nanoparticles from spontaneous reduction of silver (I) in DMSO. Interaction between nitric oxide and silver nanoparticles. J Phys Chem B 106(10):2482-2487

Sands DE (1993) Introduction to crystallography. Dover, New York, p 51

Sharma B, Purkayastha DD, Hazra S, Thajamanbi M, Bhattacharjee CR, Ghosh NN, Rout J (2014) Biosynthesis of fluorescent gold nanoparticles using an edible freshwater red alga, Lemanea fluviatilis (L.) C. Ag. and antioxidant activity of biomatrix loaded nanoparticles. Bioprocess Biosyst Eng 37(12):2559-2565

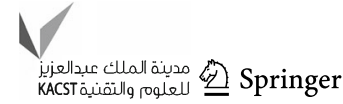


Shetty P, Supraja N, Garud M, Prasad TNVKV (2014) Synthesis, characterization and antimicrobial activity of Alstonia scholaris bark-extract-mediated silver nanoparticles. J Nanostruct Chem 4(4):161-170

Shriram V, Kumar V, Shitole MG, Shriram V, Kumar V, Shitole MG (2008) Indirect organogenesis and plant regeneration in Helicteres isora L. an important medicinal plant. In Vitro Cell Dev Biol Plant 44(3):186-193

Singh SB, Singh AK, Thakur RS (1984) Chemical constituents of the leaves of Helicteres isora. Ind $\mathrm{J}$ Pharmaceu Sci 46(4): 148-149

Singh S, Saikia JP, Buragohain AK (2013) A novel 'green' synthesis of colloidal silver nanoparticles (SNP) using Dillenia indica fruit extract. Coll Surf B Biointerfaces 102:83-85

Sousa A, Ferreira ICFR, Barros L, Bento A, Pereira JA (2008) Effect of solvent and extraction temperatures on the antioxidant potential of traditional stoned table olives "alcaparras". Food Sci Technol-LWT 41:739-745
Suthar M, Rathore GS, Pareek A (2009) Antioxidant and antidiabetic activity of Helicteres isora (L.) fruits. Indian J Pharm Sci 71(6):695

Venkadesh S, Reddy GD, Reddy YSR, Sathyavathy D, Reddy BM (2004) Effect of Helicteres isora root extracts on glucose tolerance in glucose-induced hyperglycemic rats. Fitoterapia 75:364-367

Viet Quang D, Hoai Chau N (2013) The effect of hydrothermal treatment on silver nanoparticles stabilized by chitosan and its possible application to produce mesoporous silver powder. J Powder Technol 2013:1-6

Weiss J, Takhistov P, Mc Clements J (2006) Functional materials in food nanotechnology. J Food Sci 71(9):R107-R116

Wong KKY (2012) "Silver nanoparticles in medicine: is the panacea here", Nanomedicine: nanotechnology. Biol Med 8(6):935-940

Yang EJ, Kim S, Kim JS, Choi IH (2012) Inflammasome formation and IL-1 $\beta$ release by human blood monocytes in response to silver nanoparticles. Biomaterials 33(28):6858-6867 